\title{
Organizational Commitment and Associated Factors Among Health Professionals Working in Public Health Facilities of Benchsheko Zone Southwest Ethiopia
}

Dereje Alemayehu ( $\sim$ derejealemayehu300@gmail.com )

Mizan Tepi University

Shimeles Ololo

Jimma University

Yibeltal Siraneh

Jimma University

\section{Research Article}

Keywords: Organizational commitment, Health professionals, Public health facilities, Bench Sheko zone

Posted Date: March 11th, 2021

DOl: https://doi.org/10.21203/rs.3.rs-289827/v1

License: (c) (1) This work is licensed under a Creative Commons Attribution 4.0 International License.

Read Full License 


\section{Abstract}

Background: Organizational commitment is the relative strength of an individual's identification with and involvement in a particular organization. It is an important predictor of absenteeism, turnover, organizational performance and success. Even though organizational commitment has a paramount importance for health care organizations, very few studies were done so far in Ethiopia particularly among health professionals. Therefore, the aim of this study was to measure level of organizational commitment and associated factors among health professionals working in public health facilities of Bench Sheko zone southwest Ethiopia.

Methods: Facility based cross-sectional study was conducted in 14 Public health facilities found in randomly selected districts of Bench Sheko zone. Structured self-administered questioner was used to collect data from a total of 610 Health professionals from 10th of March - 30th of April. Data were entered into Epi-data manager Version 3.1 and exported to SPSS version 24 for further analysis. Factor analysis was done to create factor scores. Simple and multiple linear regression were done. Variables with $p$-value $\leq 0.25$ in simple linear regression were candidate for multiple linear regression. Independent sample t-test and one-way ANOVA were done. Statistical significance was declared at $p$-value $\leq 0.05$.

Results: The response rate of the study was $96.8 \%$. The percentages mean score of organizational commitment of health professionals' was $74.6 \%$. Perceived recognition of employees (B $0.806[95 \% \mathrm{Cl}$ : 0.711 - 1.00, $\mathrm{p}=0.000$ ], perceived conducive work climate (B: 0.421 [95\% Cl: .322 - 0.520], perceived transformational leadership style (B 0.749 [95\% Cl: .604 - .894, $\mathrm{p}=0.000$ ], perceived transactional leadership styles (B: 0.294 [95\% Cl: .198 - .390 p=0.000] and not having managerial position(B:-.293 [95\%Cl:-.559-0.028] were predictors of organizational commitment.

Conclusion: Overall level of organization commitment of health professionals' was higher than what is reported in many other studies. Organizational commitment was affected by job satisfaction, leadership styles and managerial position of health professionals. Hence, policy makers and human resource managers need to pay special attention to intervene on these factors.

\section{Introduction}

Organizational commitment is often defined as a force that connects employees to a course of action that is significant to certain kind of targets(1). Organizational Commitment is among types of commitment which is defined as a psychological bond characterized by employees' feeling of attachment, obligation and loyalty to a given organization. It has three components namely; affective, continuance and normative commitments. Affective commitment is employee's emotional attachment to, identification with and involvement in the organization. Normative commitment refers to employees' feelings of responsibility to the organization. Continuance commitment is about employees' evaluation of whether the costs of leaving the organization are greater than the costs of staying. Employees who 
perceive that the costs of leaving the organization are greater than the costs of staying will remain with the organization(2).

According to World Health Organizations'(WHO) framework of health system Human Resources for Health (HRH) is among the vital components of health system(3). Availability of Health Work Forces (HWF) in; adequate number, skill-mix, distribution, motivation, competence and quality are among the important factors for effective and efficient health service delivery. Unfortunately, nations at all levels of socioeconomic status wherever in the world face challenges in HWF in different extent in terms of their production, deployment, retention and proper utilization $(4,5)$. Organizational commitment is linked with both positive and negative consequences for health sectors. Highly committed health professionals are characterized by; their strong desire to strive for achieving organizational goals, high satisfaction with their job, strong desire to stay in the organization, reduced absenteeism, decreased turnover intention, representation of staff's views toward their organization, good mental sprit, better organizational performance, their better manifestation of personal and organizational lofty goals(6). They are also characterized by their increased effort, motivation, and retention in the organization and by their sense of belongingness, affiliation and attachment to organizations. These all characteristics of committed health professionals create a favorable environment for better job performance and financial success which in turn result for the effectiveness and efficiency of organization(7).

In contrast, employees with reduced organizational commitment are characterized by reduced productivity and individual performance, feeling of discrimination in the work place, ignoring needs of others, reduced participation in organizational matters, increased absenteeism rate, late arrival to work place, lack of interest to stay in the organization, increased turnover, lack of trust from customers and lack of motivation. These ultimately results for loss of organizational effectiveness and efficiency(8). The most, important outcome of reduced organizational commitment among health professionals include high turnover rate, loss of motivation, job dissatisfaction and reduced performance level which subsequently results for loss of service care, organizational efficiency and reduction in patient satisfaction(9).

Additionally, lack of organizational commitment among health professionals will account to; increased occurrence of medical errors (endangering patient safety), increases in the longevity of inpatient day admissions and redundancy of hospitalizations(8). It also results in reduction of patient satisfaction towards health service delivered, inflation of medical costs(9), interruptions of normal operations and loss of efficiency(10). All these poor organizational commitment related problems will finally lead too low quality of health care. However, higher levels of commitment to organization are likely to; result in reduction of employee turnover intention, reduce staff absenteeism and provide organizations with stable and dedicated workforce. This lowers employee recruiting, training and development costs for organizations and increase organizational job performance which in turn accounts for enhancement of organizational performance (10). The magnitude of organizational commitment of health professionals found to be variable across the world. For instance, studies from Iran, Philippines and Egypt found to be $52.1 \%, 3.13(31.3 \%)$ and $63.9 \%$, respectively(11-13). In Ethiopia studies from West Amhara, Gurage zone 
and Jimma University Specialized and Teaching Hospital (JUSTH)reported, 52.82\%, 64.81\% and $88 \%$ level of organizational commitment among health professionals respectively(14-16). Studies suggested that magnitude of organizational commitment of health professionals are associated with factors such as motivation of employees, job performance(10),perceived organizational support(POS), interpersonal relationship, job satisfaction, transformational leadership behavior, educational qualification, working ward(16), perceived leadership style, training opportunity, perceived value and care for employee, perceived remuneration, perceived staff interaction, perceived resource availability, work setting(15) and employee empowerment(17).

Concerning, research gap on organizational commitment of employees, Kossivi and Ming, in their recent review on organizational commitment in China, noted the presence of literature gap in nonwestern parts of the world in the subject matter(18). In Ethiopia, based on search of published literatures and to the extent of the investigator's knowledge, so far three studies were done on organizational commitment of health professionals. These were a studies done in West amhara Gurage zone and JUSTH(14-16).

Although these studies came up with important findings, they had certain limitations. The study done in West Amhara didn't identify factors associated with organizational commitment of health professionals. That of study done in JUSTH has been limited on one profession (nurses) and one organization (Jimma university teaching and specialized hospital). On the other hand,the study done in Gurage zone did not assess the effect of perceived leadership style on organizational commitment of health professionals. Common limitation of these studies were they did not assess the effect of employee empowerment on organizational commitment of health professionals.

Kossivi and Ming, in their review recommended future studies to identify factors affecting organizational commitment in nonwestern context(18). In addition, Israel and his colleagues in their study among nurses working in JUSTH(16) recommended future researchers to assess the relationship between employee empowerment and organizational commitment of health professionals. Therefore, this study attempted to address this gap to identify factors affecting organizational commitment among health professionals and the extent to which these problems exist in public health facilities of Bench sheko zone Southwest Ethiopia.

\section{Method And Materials}

\section{Study area and period}

The study was conducted in selected public health facilities of Bench Sheko Zone, Southrn Nations Nationalities and Peoples Regional State (SNNPR) state, south west Ethiopia, from March 20- April 30, 2020. Bench sheko Zone is one of the 15 zones of SNNR State of Ethiopia. Mizan Aman Town, is the capital of the Zone, which is located $585 \mathrm{~km}$ away from Addis Ababa. The total estimated population of the zone is 625345 . The zone has 8 districts, 6 rural and 2 town administration with 25 public health 
centers and one teaching hospital. There were 904 health professionals working in these public health facilities of Bench Sheko Zone.

Study design: Facility-based cross-sectional study.

\section{Sample size and sampling technique}

Fourteen public health facilities (thirteen health center and one hospital) were randomly selected from the 25 public health facilities found in Bench Sheko Zone. A total of 630 health professionals who worked for six month and above in the selected health facilities were included in the study. Those health professionals who had been on sick leave and steady leave during data collection were excluded from the study.

\section{Variable of the study}

\section{Dependent variable}

Organizational commitment

\section{Independent variables}

1. Socio-demographic variables: Gender, age, education level, marital status, type of profession, working health facility, year of service, having managerial position, residence, net monthly salary and housing condition.

2. Job satisfaction 3. Perceived organizational support 4. Perceived leadership style 5. Perceived psychological empowerment

\section{Operational definitions and measurements}

1. Public health facilities are hospitals and health centers that are owned by government were considered as public health facilities.

2. Organizational commitment means the relative strength of an individual's linkage to the organization. It was measured with 16 items in 5-point Likert scale ( $1=$ strongly disagree to $5=$ strongly agree). The mean score (level of organizational commitment) was reported as the percentages of scale mean score (\%SM) after calculation of standardized mean value. This value ranges from "0\%" to " $100 \%$ ". It was calculated using the formula \%SM = (Actual score -Potential minimum score/Potential maximum-Minimum) *100(19). Composite scale of organizational 
commitment score was created from the four factors emerged on factor analysis of organizational commitment items. This score was used as continuous dependent variable on linear regression.

3. Job satisfaction means positive or pleasurable emotional state resulting from the appraisal of one's job or job experience. It was measured with 2 scales (perceived conducive work climate and perceived recognition).

Perceived conducive work climate refers to situations to health professionals' work in facilities where there were good work atmosphere among professionals and between professionals and their facilities. It was measured using 3 items in 5 point Likert scale ( $1=$ very dissatisfied to $5=$ very satisfied). Perceived conducive work climate scale was created on factor analysis and higher score indicate higher job satisfaction.

Perceived recognition scale denotes career development and educational promotion opportunity in once organization. It was measured with 11 items in 5 -point Likert scale ( $1=$ very dissatisfied to $5=$ very satisfied). Perceived recognition score was created on factor analysis and higher scores indicate higher job satisfaction.

4. Perceived organizational support denotes the extent to which employees see that organizations recognizes their contribution and cares about their well-being. Perceived organizational support was measured using 2 scales; perceived value and care for employee and perceived concern for employee. Perceived value and care for employee defines job characteristic where the organization acknowledges the effort of health professionals and care for their wellbeing. This was measured using 3 items in 5 -point Likert scale ( $1=$ strongly disagree to $5=$ strongly agree). Perceived value and care for employee score was created on factor analysis and higher score indicate higher perceived organizational support.

Perceived concern for employee is the way how the organization is being open to the needs and questions of health professionals. This was measured with 4 items in 5 -point Likert scale ( $1=$ very dissatisfied to $5=$ very satisfied). Perceived concern for employee score was created on factor analysis and higher score indicate higher perceived organizational support.

Perceived leadership style refers to perception of health professionals about leadership style of their immediate leader. It was measured with 2 scales; perceived transformational leadership style and perceived transactional leadership style.

Perceived transformational leadership style measures individual's opinion about how their immediate leaders were motivating and inspiring to them and how they involve in setting good relationship. It was measured with 5 items in 5 -point Likert scale ( $1=$ strongly disagree to $5=$ strongly agree). Perceived transformational leadership style was created on factor analysis and higher score indicate higher perceived leadership style. 
Perceived transactional leadership style scale denotes perception of individual health professionals about how their leader manage or respond to situations or changes. It was measured with 2 items in 5point Likert scale ( $1=$ strongly disagree to $5=$ strongly agree). Perceived transactional leadership style was created on factor analysis and higher score indicate higher perceived leadership style.

6. Perceived psychological empowerment denotes the extent to which organizations give authority and freedom for their employees in order to do formal tasks. It was measured with 3 scales; perceived impact, perceived self-confidence and perceived self-determination.

Perceived impact denotes individual's perception about their impact and influence in their organization or working department. Perceived impact was measured using 3 items in 5-point Likert scale, which ranges from ( $1=$ strongly disagree to $5=$ strongly agree). Perceived impact score was created on factor analysis and higher scores indicate higher perceived psychological empowerment.

Perceived confidence scale measures health professionals' opinion about their ability and competence in order to fully execute their job. It was measured with 3 items in 5-point Likert scale (1=strongly disagree to $5=$ strongly agree). Perceived confidence score was created on factor analysis and higher score indicate higher perceived psychological empowerment.

Perceived self-determination scale measure health professionals' freedom and authority in the work place. It was measured with 2 items in 5 -point Likert scale ( $1=$ strongly disagree to $5=$ strongly agree). Perceived self-determination score was created on factor analysis and higher score indicate higher perceived psychological empowerment.

\section{Data collection tool}

Data were collected using structured questionnaire adapted from related literatures. The questionnaires had six parts. Part one contained socio-demographic characteristics which had 12 questions, part two comprised of job satisfaction questions with 23 items, part three was on perceived organizational support having 8 items, part four was on organizational commitment questionnaires having 24 items, part five was on perceived leadership style measures with 9 items and part six was on perceived psychological empowerment questionnaires with 12 items.

Tools from part one up to part three were adapted from related study conducted in Gurage zone southwest Ethiopia (SWE) (15). Tool for part four was adapted from organizational commitment questioners of studies of Jaros which was initially developed and validated by Meyer and Allen(20). Tool for part five was adapted from Multi factor Leadership Questionnaire (MLQ) of studies of Mora C. and Ticlau T., which was firstly developed and validated by Bass and Avolio(21). Lastly, a tool for part six was adapted from studies of Ambad S and Bahron, which was initially developed and validated by Spreitzer(22). After running factor analysis the following scales were emerged as part of the tools. 
Organizational commitment is a composite scale that was created from four factors each with Eigen value $\geq 1$, which totally explained $66.88 \%$ of the variability, which facilitated the treatment of organizational commitment as a single continuous dependent variable on linear regression. The composite scale was labeled as organizational commitment. It had sixteen items, which had a reliability coefficient (Cronbach's alpha) of 0.833 . The first factor was loaded with the following seven items.

1. One of the few serious consequences of leaving this organization would be the scarcity of available alternatives,

2. I feel that I have very few options to consider leaving this organization,

3. Too much in my life would be disrupted if I decided to leave my organization now,

4. One of the major reasons I continue to work for this organization is that leaving would require considerable personal sacrifice and besides this another organization may not match the overall benefit I have here,

5. Right now, staying with my organization is a matter of necessity as much as desire,

6. It would be very hard for me to leave my organization right now even if I wanted to,

7. If I got another offer for a better job elsewhere, I would not feel it was right to leave my organization.

The items have reliability coefficient (Cronbach's alpha) of $=0.869$. This factor was named as continuance commitment scale. It explained, $24.84 \%$ of the total variability in the organizational commitment of health professionals.

The second factor has four items;

1. Jumping from organization to organization does not seem at all unethical to me,

2. I think that I could easily attach myself to another organization as I am to this one(R),

3. I do not believe that a person must always be loyal to his or her organization(R),

4. I think that people these days move from company to company too often(R).

This factor was labeled as normative commitment scale. The items loaded in this scale have reliability coefficient (Cronbach's alpha) of $=0.769$. The scale explained $15.63 \%$ of the total variability in the organizational commitment of health professionals.

Three items were loaded on the third factor;

1. I do not feel 'emotionally attached' to this organization(R),

2. I do not feel like 'part of the family' at my organization and I do not feel a 'strong' sense of belonging to my organization.

3. I do not feel a 'strong' sense of belonging to my organization

This scale was identified as affective commitment. It has reliability coefficient (Cronbach's alpha) of 0.766. It explained $13.47 \%$ of the total variability in the organizational commitment of health 
professionals.

Lastly, two items were loaded on the fourth factor

1. I really feel as if this organization's problems are my own,

2. I enjoy discussing about my organization with people outside it.

These items have Cronbach's alpha of $=0.70$. The factor was named as perceived proud and concern scale. It explained around $10 \%$ the variability in the organizational commitment of health professionals.

Job satisfaction: Two factors each with Eigen value $\geq 1$, which explained $66.18 \%$ of the total variability in job satisfaction of health professionals were extracted.

Three items were loaded on the firs factor

1. I have good working relationship with my colleagues,

2. There is a clear channel of communication at my workplace,

3. I can depend on my colleagues for support.

This scale was named as perceived conducive work climate. The items have reliability coefficient (chronbachs alpha of 0.845 ). Perceived conducive work climate scale explained $49.12 \%$ of the total variability in the job satisfaction of health professionals.

The second factor was loaded with 11 items

1. I have enough support for continuing education,

2. I have sufficient opportunity for professional growth,

3. I get support for personal growth and development through education and training,

4. I receive recognition for the tasks well done,

5. I don't experience frustration in my workplace due to limited supply,

6. I have support to be fully accountable for those decisions,

7. My work has more advantages than disadvantage,

8. Adequate consideration is given to my opinion and suggestion for change in the work setting,

9. My income is the reflection of the work I do,

10. Adequate recognition is given to my personal needs,

11. There are training opportunities available to me.

This scale was denoted as perceived recognition. The items have reliability coefficient (Cronbach's alpha) of 0.941 . Perceived recognition explained $17.05 \%$ of the total variability in the job satisfaction of health professionals. 
Perceived organizational support: Two factors each with Eigen value $\geq 1$, which together explained $58.53 \%$ of the total variability in perceived organization support of health professionals were extracted. The following four items were loaded on the first factor

1. The organization fails to appreciate any extra effort from me(R),

2. The organization ignores any compliant that I raise $(R)$,

3. Even if I did the best job possible, the organization would fail to notice(R),

4. The organization shows very little concern for me(R). This factor was labeled as perceived concern for employee scale. Perceived concern for employee had reliability coefficient (Cronbach's alpha) of 0.723. It explained $31.3 \%$ of the total variability in the perceived organization support of health professionals. The second factor was loaded with 3 items

5. The organization values my contribution to its wellbeing,

6. The organization really cares about my wellbeing,

7. The organization cares about my general satisfaction at work.

The scale was identified as perceived value and care for employee scale. The items of this scale had reliability coefficient (Cronbach's alpha) of 0.692 . It explained $27.22 \%$ of the total variability in the perceived organizational support of health professionals.

Perceived leadership style: Two factors each with Eigen value $\geq 1$ which cumulatively explained $77.67 \%$ of the total variability in perceived leadership style of health professionals were extracted.

The first factor was loaded with the following five items

1. My manager talks optimistically about the future,

2. My manager spends time teaching and coaching me,

3. My manager reexamines critical assumptions in order to question whether they are appropriate,

4. My manager instills pride in me for being associated with him/her,

5. My manager avoids making decisions $(\mathrm{R})$.

This factor was labeled as perceived transformational leadership style. The items of this scale have reliability coefficient (Cronbach's alpha) of 0.908. Perceived transformational leadership style explained $50.42 \%$ of the total variability in the perceived leadership style of health professionals.

Two items were loaded on the second factor

1. My manager fails to interfere until problems become serious $(R)$,

2. My manager concentrates his/her full attention on dealing with mistakes, complaints and failures(R). 
This scale was identified as perceived transactional leadership style. It explained $27.24 \%$ of the total variability in the perceived leadership styles of health professionals. Perceived transactional leadership style items have Cronbach's alpha of 0.862 .

Perceived psychological empowerment: Three factors each with Eigen value $\geq 1$, which in combination explained $80.81 \%$ of the total variability in the perceived psychological empowerment of health professionals were extracted.

The first factor was loaded with three items

1. My impact on what happens in my department is large,

2. I have a great deal of control over what happens in my department,

3. I have significant influence over what happens in my department.

This factor was named as perceived impact. Perceived impact explained $30.02 \%$ of the total variability in the perceived psychological empowerment of health professionals. Perceived impact items had reliability coefficient (Cronbach's alpha) of 0.873 .

The second factor was loaded with three items

1. I am confident about my ability to do my job,

2. I have mastered the skills necessary for my job,

3. I am self-assured about my capabilities to perform my work activities.

The scale was named as perceived self-confidence. Perceived self-confidence explained $28.43 \%$ of the total variability in perceived psychological empowerment of health professionals. Perceived selfconfidence items had reliability coefficient (Cronbach's) alpha of 0.835 .

\section{Data quality control}

The questionnaire firstly prepared in English was translated into the local language (Amharic) which was back translated into English to ensure consistency. The study tools were pre-tested on 66 health professionals ( $10 \%$ of the sample size) who were not actual study participants working in a nearby public health facilities. Seven BSc. Degree holder health professionals ( 4 health officers and 3 nurses) employed as data collectors. One masters of public health student (MPH) and two assistant lecturers of public health were supervisors of the data collection. Prior to actual data collection process two days training was given for data collectors and supervisors about; general overview of organizational commitment, its effect on health care service delivery, aim of the study, data collection tools, process of data collection and the role of each data collector and supervisor from the beginning of data collection to the end.

\section{Data processing and analysis}


Data were entered into Epi-data Version 3.1 and exported to SPSS version 24.0 for analysis. The frequency distribution of all the variables was examined to check for data entry errors. Assumptions of factor analysis and linear regression were checked. Simple and multiple linear regression were done. Variables with $p$-value $\leq .25$ on simple linear regression were candidate for multiple linear regression model. Hierarchal linear regression with enter method were done to build the final multiple regression model. Predictors of organizational commitment were declared in the final model at a significance level of $p$-value $\leq 0.05$. Independent sample t-test and one-way ANOVA were done to check the presence of significant mean difference in organizational commitment between and among categories of categorical sociodemographic variables respectively. Finally, findings were presented using; figures, raw means, standard deviations, percentage mean scores and summary tables.

\section{Ethical considerations}

The current study was conducted in accordance with declaration of Helsinki. Ethical clearance letter was obtained from institutional review board of Institute of health of Jimma University. In addition, support and permission letter were obtained from Zonal, Woreda health departments. Prior to starting data collection process written informed consent was taken from each study participants. Participant's right to participate and withdraw from the study was assured.

\section{Result}

\section{Socio demographic characteristics of respondents}

Among, 663 eligible health professionals working in Bench Sheko zone public health facities, 630 of them fulfilled the inclusion criteria (33 did not fulfilled the inclusion criteria) and 630 questioners were distributed for health professionals active during data collection period. However, 610 Health professionals were correctly filled and returned the questioners yielding a response rate of $96.8 \%$ (610/630). From the remaining 20 questioners five were incomplete and 15 were not filled at all. Among, 610 respondents nearly two-third (61.6\%) were males. A little more than half of the respondents $(53.7 \%)$ were married followed by single (43.4\%). The median age of the participants was 28year (IQR=4). Almost, half of respondents (47\%) had 6month to 2 years of work experience at the current working health facility. With professional background a little more than two-fifth (40.8\%) were nurses. Three-fifth $(60.3 \%)$ of respondents had college diploma. Four hundred seventy two (77.4\%) were from urban resident and three hundred forty three $(56.2 \%)$ work in health center. Eighty six $(14.1 \%)$ worked in a managerial position. Fifty $(8 \%)$ of the participants reside within the compound of health facility. The median net monthly salary of health professionals was 3137 Ethiopian Birr (85.94 USD) (IQR=1478) (Table-1).

Level of organizational commitment: The overall level of organizational commitment (percentage means score) of health professionals participated in this study was $74.6 \%$ (SM \%) with mean raw score of 58.09 \pm 11 .3. On the other hand, the percentage mean score of individual components of OC were; $73.1 \%$ for 


\section{Predictors of organizational commitment}

\section{Socio demographic predictors of organizational commitment}

These model consists socio demographic variables like; age, gender, marital status, educational level, year of service, type of profession, type of working facility, havening managerial position, residence, net monthly salary and place of living house. Among, these variables sex, age, marital status, type of profession, year of service, havening managerial position and place of living house had statically significant association with organizational commitment in bivariate simple linear regression model at $p$ value $\leq 0.25$. They were included in the multiple linear regression model. These variables explained $5.9 \%$ of the variability in organizational commitment of health professionals.

\section{Perceived organizational support related predictors of organizational commitment}

In this model, two factors related with perceived organizational support were entered. Perceived value and care for employee had no statistically significant predictive effect on organizational commitment of health professions ( $p=0.329, B, .087,95 \% \mathrm{Cl}:-.302,058)$. On the other hand, perceived concern for employee was a significant predictor of organizational commitment of health professionals $(p=.184$, $\mathrm{B}=0.087,95 \% \mathrm{Cl}=-.302,0.058)$ at $\mathrm{p}$-value $\leq 0.25$.

This model explained only $1 \%$ (adjusted $\mathrm{R}$ square $=0.001$ ) of the variance in organizational commitment of health professionals.

Job satisfaction related predictors of organizational commitment: Two factors related with job satisfaction of health professionals were entered in to this model. Two of these factors were strong predictors of organizational commitment of health professionals.

Perceived recognition $(B=1.43,95 \% \mathrm{Cl}=1.327,1.536)$ followed by perceived conducive work climate $(B=0.474,95 \% \mathrm{Cl}=0.369,0.579)$. Almost, $57 \%$ of the variance in $\mathrm{OC}$ of health professionals was explained by this model (adjusted R square $=0.567, p=0.001$ ).

Perceived leadership style related predictors of organizational commitment: In this model, two factors related with perceived leadership style were entered. Both of them had statistically significant association with organizational commitment of health professionals at $p$ value $\leq 0.25$. 
Perceived transformational leadership style $B=1.436(95 \% \mathrm{Cl}=1.330,1.541)$, Perceived transactional leadership style (B .425 (95\% Cl=.320, .531). This model explained $56 \%$ of the variance in the OC of health professionals (adjusted R square $=0.559, \mathrm{p} \leq 0.25$ ).

Perceived psychological empowerment related predictors of organizational commitment. Three factors related with perceived psychological empowerment of health professionals were entered in this model out of which two factors were significant predictors of organizational commitment of health professionals at $p$ value $\leq 0.25$. Perceived impact $(B=0.120,95 \% C l=-.038,0.278)$ and perceived self-confidence $(B=0.235$, $95 \% \mathrm{Cl}=0.077,0.393)$. This model explained only $1.5 \%$ of the variance in $\mathrm{OC}$ of health professionals (adjusted R square $=0.015, \mathrm{p} \leq 0.25$ ).

\section{Independent predictors of organizational commitment}

Those variables, which had statistical significant association with organizational commitment of health professionals in preceding models were entered into the final model. The final model explained almost $68 \%$ (Adjusted R Square $=.677$ ) of the total variability in the organizational commitment of health professionals working in public health facilities of Bench sheko zone SWE.

Having managerial position was the only socio demographic variable which significantly associated with organizational commitment of health professionals in the final model. In this respect, health professionals who had no managerial position had 0.293 unit decreased commitment to their organization than their counter parts, keeping other independent variables constant $(95 \% \mathrm{Cl}:-.559,-.028)$.

Our study found that leadership style having significant association with organizational commitment of health professionals. In this regard, a unit increase in perceived transformational leadership style of health professionals was significantly associated with .749 unit positive increase in their organizational commitment, keeping other predictor variables constant $(95 \% \mathrm{Cl}$. $604, .894)$. Similarly, a unit increase in perceived transactional leadership style of health professionals was significantly associated with .294 unit more increase with their organizational commitment, keeping other independent variables constant (95\%Cl: .198, .390).

Job satisfaction was the other variable which significantly associated with organizational commitment of health professionals in our finding. Among, job satisfaction related factors perceived recognition of health professionals were the strongest predictor of organizational commitment of health professionals in the current study. In line, with this one unit increment in the perceived recognition of health professionals was significantly associated with .856 unit higher increment in their organization commitment keeping other predictor factors constant (95\% Cl: .711, 1.00). Perceived conducive work climate scale was also job satisfaction related factor which significantly predicted organizational commitment of health professionals. In this respect a unit increment in perceived conducive work climate of health professionals was significantly associated with .421 unit more increase in their organizational commitment keeping other independent variables constant(95\% Cl: .322, .520) (Table-3). 


\section{Discussion}

This study was conducted with the aim of assessing level of organizational commitment and associated factors of health professionals working in public health facilities of Bench sheko zone SWE. According, to our study the level of organizational commitment of health professionals was $74.6 \%$ (\%SM) and perceived recognition, perceived conducive work climate, perceived transformational leadership style, perceived transactional leadership styles and having managerial position were factors significantly associated with organizational commitment of health professionals. Our finding, $74.6 \%$ (\%SM) is higher than studies conducted in Iran(11), West Amhara(14) and Gurage zone(15), where the \%SM were $52.1 \%$, $52.82 \%$ and $64.81 \%$ respectively.

The discrepancy in Iran is more likely explained by methodological differences employed in the sample size $(n=126)$ and inclusion criteria (nurses only, with at least 1 year of service, who have minimum of BSc or MSc in nursing profession). In particular, educational level of the study participants can create a great disparity in understanding organizational commitment questions, which intern significantly contribute for variation of organizational commitment level11).

Unlike, study conducted in west Amhara(14), almost more than half of participants of the current study were from health centers. Usually, health centers have low work load and client flow as compared to hospitals. This might be one possible reason for better level of organizational commitment in our study. With regard to, study conducted in Gurage zone(15) the discrepancy could be due to the difference in the number of items and level of Likert scale used to measure organizational commitment. Our study, is measured with 16 items in a 5 point Likert scale, whereas study conducted in Gurage zone (13) was measured with 9 items in a 7 point Likert scale(15).

However, the current finding $74.6 \%$ (\%SM) is lower than study conducted in jimma university specialized and teaching hospital (JUSTH) where the SM\% was $88.06 \%(16)$. The context of our study differs in some extent that of study done in JUSTH where in our case multiple health facilities ( 1 hospital and 13 health centers) with variety of health professional categories participated, whereas in JUSTH only nurses participated. Moreover, in our study area most of the health facilities were located in remote areas which is far from zonal, regional and national capital cities. These locations are related for health professionals with poor access to basic infrastructures like access to; road, transportation, educational opportunities and institutions and recreation centers. These might be among, the possible factors for the low level of organizational commitment in our study. This study found significant and positive association between job satisfaction and organizational commitment of health professionals. This is the most important finding from our study which has support from theories. Accordingly, Abraham Maslow's Hierarchy of Needs Theory strengthens this which stated that satisfied employees will have higher commitment to their organization(23). Job satisfaction in terms of perceived recognition and perceived conducive work climate were significant predictors of organizational commitment of health professionals in the present study. This is congruent with previous studies from Ethiopia where job satisfaction of health professionals were significantly associated with their organizational commitment $(15,16)$. 
The current study indicated that one unit increase in perceived recognition of health professionals is significantly associated with positive increment in their organizational commitment. This could be explained by the importance of having recognition for health professionals, which creates conducive environment for their future promotion, professional and career growth.

The importance of recognition for employees was also emphasized by Abraham Maslow's hierarchy of needs theory which stated that "employees want to be respected and appreciated by their co-workers and their bosses". Furthermore, employee's image of himself and his desire for the respect and recognition of others are linked with esteem needs(23).

Perceived conducive work climate of health professionals was another factor which significantly associated with organizational commitment of health professionals in this study. Health facilities working environment contributes a significant role in the capacity to deliver quality client service. Working environment in whatever kind of health facility has a direct influence on everything from the health professionals their job satisfaction to patient safety. On the other hand, poor working climate can predispose for issues like: under staffing, shorter tenure and poor patient outcome(24).

The present study suggested that health professionals who score higher for perceived conducive work climate are more committed to their organization. This is correspondent, with previous studies from Philippines and Pakistan(25)(26). Abraham Maslow under his theory of hierarchy of needs, stressed the role of conducive work environment for employees, stating "stable physical and emotional environment and fair work place plays an important role in achieving the wider organization's strategy and goal" (23). Perceived leadership style was the other variable which significantly and positively associated with organizational commitment of health professionals in the current study. This could be explained by wide range implications of leadership in healthcare organizations. Effective leadership promotes a quality work environment, organizational culture, positive safety climate and effective performance in health care which in turn has an impact on organizational commitment and job satisfaction of health professionals $(15,16,26,27)$.

Our study, showed that a unit increase in perceived transformational leadership style of health professional's significantly associated with positive increase in their organizational commitment. This is in agreement with study from Saudi Arabia where perceived transformational leadership style of health professionals found being significant and strong predictor of organizational commitment of nurse managers(26). This could be due to the ability of transformational leaders to work with their followers or employees. In accordance, with this transformational leader is well known by developing futuristic plan, inspiring followers to achieve results beyond normally expected from them and to surpass their own interests for the goals of the organization(28). Perceived transactional leadership style was the other perceived leadership style related factor which significantly predicted organizational commitment of health professionals in the present study. In this regard a unit increase in perceived transactional leadership style of health professionals' is significantly associated with higher increase in their organizational commitment. This is compatible with study from Saudi Arabia where perception of 
transactional leadership among health professionals is significantly associated with positive increase in organizational commitment of nurse managers(26). In addition, to aforementioned explanations for the strong association of leadership style and organizational commitment of health professionals in our study, the other possible explanation could be the context of this study. As discussed above most, of the health facilities in the current study are located in remote areas where health professionals cannot easily access basic infrastructures for their day to day job activities and routine life like; transportation, electric city and network services. It is obvious, that with these all situation in the work place maintaining commitment of health professionals requires effective leadership.

In the current study having managerial position was the only sociodemographic variable which significantly associated with organizational commitment health professionals. This is in contrary to study done in Gurage zone(15). According, to our finding health professionals working in no managerial position had lowered organizational commitment than their counter parts. Our finding, could be due to the role of having managerial position (post) for health professions which is frequently linked with chance of getting additional benefit packages like; training, increment in salary and educational opportunities. The current study is not free of limitations. That is participant bias could be limitation for our study. Except socio demographic variables all independent variables were Likert scale type which were scored by participants and they might over scored values other than their actual score. To overcome such kind of limitation training was given for data collectors to help participants fully understand objective of the study and importance of their participation.

\section{Conclusion And Recommendations}

In the light of our finding, it was concluded that the level of organizational commitment of health professionals working in public health facilities of Bechsheko zone was higher than what is reported in many other studies. Perceived conducive work climate, perceived recognition, perceived transformational leadership style, perceived transactional leadership style and having managerial position were factors significantly associated with organizational commitment of health professionals. Hence, concerned stake holders are recommended to make interventions on these factors.

\section{Abbreviations}

$\mathrm{OC}$, Organizational commitment, $\mathrm{HRH}$, Human resource for health, JUSTH, Jimma university teaching and specialized hospital, WHO, World health organization, HWF, Health work force

\section{Declarations}

\section{Ethics approval and consent to participate}

The current study was conducted in accordance with declaration of Helsinki. Ethical clearance letter was obtained from institutional review board of Institute of health of Jimma University. Participants were 
informed about the purpose of the study, and oral consent was obtained from each study participant. In addition, support and permission letter were obtained from Zonal, Woreda health departments. Prior to starting data collection process written informed consent was taken from each study participants. Participant's right to participate and withdraw from the study was assured.

\section{Consent for Publication}

Not applicable

\section{Availability of Data and Materials}

The datasets analyzed during the current study are available from the corresponding author upon reasonable request.

\section{Conflict of Interests}

The authors declare that they have no competing interests.

\section{Funding}

We did not receive any fund for this research.

\section{Authors' contributions}

DS involved in the conception of the study. DS, SO, YS, involved in the design, data collection process, analysis and interpretations of the findings. DA prepared the final draft of the manuscript. All authors read and approved the final manuscript.

\section{Acknowledgments}

We present our deepest gratitude to Department of Health policy and management of Jimma University, for giving this chance to conduct our study in successful manner. We are also grateful for our data collectors, study participants, Bench sheko Zone Health Department and woreda health offices.

\section{References}

1. Cohen A. Multiple commitment in the work place: An integrative approch. 2003. 
2. Al-shurafat MS, Binti B, Halim A. A review of organisational culture and organizational commitment. 2018;20(3):21-6.

3. WHO. Monitoring the building blocks of health system: A handbook of indicators and their measurment strategies. 2010;

4. Haileamlak A. How Can Ethiopia Mitigate the Health Workforce Gap to Meet Universal Health Coverage? 2016;2025(5):249-50.

5. Abay S. Improving the Health Workforce Distribution in Remote and Rural Areas of Ethiopia: An Evidence-Based Policy Brief. J Invest Manag. 2018;7(2):45.

6. Yaldez K. Zein EIDin RMAER. The Relationship between Nurses' Perceived Pay Equity and Organizational Commitment. Life Sci. 2013;10(2).

7. Hossein M, Naghneh K, Tafreshi MZ, Naderi M, Shakeri N, Bolourchifard F, et al. The relationship between organizational commitment and nursing care behavior. Electron Physician. 2017;9(7):483540.

8. Chen SY, Wu WC, Chang CS, Lin CT, Kung JY, Weng HC, et al. Organizational justice, trust, and identification and their effects on organizational commitment in hospital nursing staff. BMC Health Serv Res [Internet]. 2015;15(1):1-17. Available from: http://dx.doi.org/10.1186/s12913-015-1016-8

9. Bagraim JJ. Commitment and the emigration intentions of South African professional nurses. Heal SA Gesondheid. 2013;18(1):1-7.

10. Masud $\mathrm{H}$. Human resource management practices and organizational commitment: Research methods, issues, and future directions. 2019;8(1):217-26.

11. Sepahvand F, Atashzadeh-shoorideh F, Parvizy S, Tafreshi MZ, Beheshti S. The relationship between some demographic characteristics and organizational commitment of nurses working in the Social Security Hospital of Khorramabad. Electron Physician (ISSN 2008-5842). 2017;9(6):4503-9.

12. Labrague LJ, Mcenroe DM, Tsaras K, Cruz JP, Colet PC, Gloe DS. International Journal of Nursing Sciences Organizational commitment and turnover intention among rural nurses in the Philippines: Implications for nursing management. Int J Nurs Sci [Internet]. 2018;5(4):403-8. Available from: https://doi.org/10.1016/j.jinss.2018.09.001

13. Mubarak R, Ahmed E, Elguindy H. Staff nurses ' intention to leave nursing profession and their organizational commitment in selected hospitals at Beni-Sueif City. (January 2017).

14. Zemichael Weldegebriel, Yohannes Ejigu, Fitsum Weldegebreal MW. Motivation of health workers and associated factors in public hospitals of West Amhara , Northwest Ethiopia. 2016;159-69.

15. Gebremariam Hailemicael Nima, Mirkuzie Woldie Kerie GTN. Organizational commitment of health professionals and associated factors in government health facilities of Gurage zone, south Ethiopia. ,2016. 5(5):82-90.

16. Israel B, Kifle W, Tigist D, Fantahun W. Organizational commitment and its predictors among nurses working in Jimma University Specialized Teaching Hospital , Southwest Ethiopia. ,2017. 
17. Ali A, El S, Mostafashazly M, Abdelrahman M. Relationship between empowerment and organizational commitment among staff nurses. 2018;7(1):17-24.

18. Kossivi Bodjrenou, Ming Xu KB. Antecedents of organizational commitment: A review of personal and organizational factors. 2019;276-89.

19. Yibeltal S, Shimels O, Mirkuzie W, Gebeyehu T, Kiddus Y, Ayinegida A, Belay E MH. Level and Factors Associated with Professional Commitment of Health Professionals Providing Institutional Delivery Services in Public Health Facilities, Southwest Ethiopia.

20. Jaros S. Meyer and Allen Model of organizational commitment: Measurement issues. 2015;(April).

21. Kebriaei A, Rakhshaninejad M, Mohseni M. Influence of Psychological Empowerment on Organizational Commitment among Medical Employees in a Hospital Setting. 2016;(October 2015).

22. Ambad S, Bahron A. Psychological empowerment: The influence on organizational commitment among employees in the construction sector. J Glob Bus Manag. 2012;8(2):73.

23. Maslow A. Hierarchy of Needs ( Content Theory ); 1943:1-4.

24. Khan AS, Jan F. The Study of Organization Commitment and Job Satisfactionamong Hospital Nurses. A Survey of District Hospitals of Deralsmail Khan. 2015;15(1).

25. Mubarak R, Ahmed E, Elguindy H. Staff nurses ' intention to leave nursing profession and their organizational commitment in selected hospitals at Beni-Sueif city. (January 2017).

26. Paul MA, Roger G. Leadership style and organisational commitment among nursing staff in Saudi Arabia. 2018;(October 2017):531-9.

27. Danae F. Sfantou, Aggelos Laliotis, Athina E. Patelarou, Dimitra Sifaki- Pistolla MM and EP. Importance of leadership style towards quality of care measures in healthcare settings: A systematic review. 2017;

28. Jain P. The role of transformational leadership in organizational commitment. 2015;2(5):1-11.

\section{Tables}


Table-1

Sociodemographic characteristics of health professionals working in Public health facilities of Bench sheko Zone SWE $(n=610)$.

\begin{tabular}{|c|c|c|c|}
\hline \multicolumn{2}{|l|}{ Socio demographic variables } & \multirow{2}{*}{$\begin{array}{l}\text { Frequency } \\
377\end{array}$} & \multirow{2}{*}{$\begin{array}{l}\text { Percent } \\
61.8 \%\end{array}$} \\
\hline Gender & Male & & \\
\hline & Female & 233 & $38.2 \%$ \\
\hline \multirow[t]{4}{*}{ Marital status } & Married & 328 & $53.8 \%$ \\
\hline & Single & 265 & $43.4 \%$ \\
\hline & Divorced & 14 & $2.3 \%$ \\
\hline & Widowed & 3 & $0.5 \%$ \\
\hline \multirow[t]{7}{*}{ Field of specialization } & Nurse & 254 & $41.7 \%$ \\
\hline & Midwifery & 79 & $12.9 \%$ \\
\hline & Health officer & 76 & $12.5 \%$ \\
\hline & Laboratory professional & 59 & $9.7 \%$ \\
\hline & Pharmacist & 53 & $8.7 \%$ \\
\hline & Medical doctors & 48 & $7.8 \%$ \\
\hline & Others & 41 & $6.7 \%$ \\
\hline \multirow[t]{3}{*}{ Educational level } & Diploma & 368 & $60.3 \%$ \\
\hline & First degree & 239 & $39.2 \%$ \\
\hline & Post graduate & 3 & $0.5 \%$ \\
\hline \multirow[t]{4}{*}{ Year of service } & 6Month-2year & 287 & $47 \%$ \\
\hline & 2.1 year -5 year & 191 & $31.3 \%$ \\
\hline & 5.1 year - 10 year & 109 & $17.9 \%$ \\
\hline & $>10$ year & 23 & $3.8 \%$ \\
\hline \multirow[t]{2}{*}{ Residence } & Urban & 472 & $77.4 \%$ \\
\hline & Rural & 138 & $22.6 \%$ \\
\hline \multirow[t]{2}{*}{ Type of facility you are working } & Health center & 344 & $56.4 \%$ \\
\hline & Hospital & 266 & $43.6 \%$ \\
\hline Type of post & Non managerial & 521 & $85.4 \%$ \\
\hline
\end{tabular}




\begin{tabular}{|llll|}
\hline Socio demographic variables & & Frequency & Percent \\
\hline & Managerial & 89 & $14.6 \%$ \\
\hline Place of living house & Outside compound of health facility & 558 & $91.5 \%$ \\
\hline \multicolumn{2}{|l}{ Key (other) = Anesthesia, Emergency surgeons and Health informatics professionals } \\
\hline
\end{tabular}

Table -2

Mean score of organizational commitment of Health professionals working in Public health facilities of Bench sheko zone SWE, 2020 $(n=610)$

\begin{tabular}{|lll|}
\hline Emerged factors & Mean raw score \pm SD & $\% S M$ \\
\hline Continuance commitment & $25.6 \pm 6.9$ & $73.1 \%$ \\
\hline Normative commitment & $14.5 \pm 4.42$ & $72.5 \%$ \\
\hline Affective commitment & $11.9 \pm 2.8$ & $79.3 \%$ \\
\hline Perceived proud and concern & $7.49 \pm 2.2$ & $74.9 \%$ \\
\hline Organizational commitment & $58.09 \pm 11.3$ & $74.6 \%$ \\
\hline
\end{tabular}

Table-3 Independent predictors of organizational commitment of health professionals working in public health facilities of Bench sheko zone SWE, $2020(n=610)$ 




